\title{
Basinwide Integrated Volume Transports in an Eddy-Filled Ocean
}

\author{
T. KANZOW \\ Ozeanzirkulation und Klimadynamik, Leibniz-Institut für Meereswissenschaften an der Universität Kiel, Kiel, Germany, and \\ Ocean Observing and Climate Research Group, National Oceanography Centre, Southampton, Southampton, United Kingdom \\ H. L. JOHNSON \\ Department of Earth Sciences, University of Oxford, Oxford, United Kingdom \\ D. P. MARSHALL \\ Atmospheric, Oceanic and Planetary Physics, Clarendon Laboratory, University of Oxford, Oxford, United Kingdom \\ S. A. Cunningham, J. J.-M. Hirschi, A. Mujahid, And H. L. Bryden \\ Ocean Observing and Climate Research Group, National Oceanography Centre, Southampton, Southampton, United Kingdom \\ W. E. JOHNS \\ Division of Meteorology and Physical Oceanography, Rosenstiel School of Marine and Atmospheric Science, Miami, Florida
}

(Manuscript received 14 November 2008, in final form 16 June 2009)

\begin{abstract}
The temporal evolution of the strength of the Atlantic Meridional Overturning Circulation (AMOC) in the subtropical North Atlantic is affected by both remotely forced, basin-scale meridionally coherent, climaterelevant transport anomalies, such as changes in high-latitude deep water formation rates, and locally forced transport anomalies, such as eddies or Rossby waves, possibly associated with small meridional coherence scales, which can be considered as noise. The focus of this paper is on the extent to which local eddies and Rossby waves when impinging on the western boundary of the Atlantic affect the temporal variability of the AMOC at $26.5^{\circ} \mathrm{N}$. Continuous estimates of the AMOC at this latitude have been made since April 2004 by combining the Florida Current, Ekman, and midocean transports with the latter obtained from continuous density measurements between the coasts of the Bahamas and Morocco, representing, respectively, the western and eastern boundaries of the Atlantic at this latitude.

Within $100 \mathrm{~km}$ of the western boundary there is a threefold decrease in sea surface height variability toward the boundary, observed in both dynamic heights from in situ density measurements and altimetric heights. As a consequence, the basinwide zonally integrated upper midocean transport shallower than $1000 \mathrm{~m}$-as observed continuously between April 2004 and October 2006-varies by only $3.0 \mathrm{~Sv}\left(1 \mathrm{~Sv} \equiv 10^{6} \mathrm{~m}^{3} \mathrm{~s}^{-1}\right)$ RMS. Instead, upper midocean transports integrated from western boundary stations 16,40 , and $500 \mathrm{~km}$ offshore to the eastern boundary vary by $3.6,6.0$, and $10.7 \mathrm{~Sv}$ RMS, respectively.

The reduction in eddy energy toward the western boundary is reproduced in a nonlinear reduced-gravity model suggesting that boundary-trapped waves may account for the observed decline in variability in the coastal zone because they provide a mechanism for the fast equatorward export of transport anomalies associated with eddies impinging on the western boundary. An analytical model of linear Rossby waves suggests a simple scaling for the reduction in thermocline thickness variability toward the boundary. Physically, the reduction in amplitude is understood as along-boundary pressure gradients accelerating the fluid and rapidly propagating pressure anomalies along the boundary. The results suggest that the local eddy field does not dominate upper midocean transport or AMOC variability at $26.5^{\circ} \mathrm{N}$ on interannual to decadal time scales.
\end{abstract}

Corresponding author address: T. Kanzow, Ozeanzirkulation und Klimadynamik, Leibniz-Institut für Meereswissenschaften, Universität Kiel, Düsternbrooker Weg 20, 24105 Kiel, Germany.

E-mail: tkanzow@ifm-geomar.de 